\title{
A Panel Data Analysis of Crime in South Africa
}

\author{
F L E Blackmore
}

Department of Economics, University of Pretoria

\section{ABSTRACT}

This study analyses the determinants of crime in South Africa using economic, social and demographic variables. The model is estimated using an unbalanced panel of 1044 observations for 15 crimes across the 9 provinces of South Africa over 8 years. A comprehensive analysis of the crime situation is achieved using this data, since it combines the benefits of macroeconomic time series with microeconomic cross sectional series. The statistical results identify significant effects for the income per capita, drug use, ratio of woman to men, the economically active population, degree of urbanisation, unemployment rate and age structure variables. Only one third of all crimes are sensitive to changes in quantity of expenditure on total protection services. Education and change in gross domestic product variables yielded insignificant results.

JEL C10, D14, E24, J1

\section{INTRODUCTION}

South Africa, with its population of 44 million, 39 percent of whom are under the age of fifteen, has undergone tumultuous change over the past few years as the authorities came to terms with existing inequalities, generations of neglect, and a developmental backlog created as a result of years of disruption and student unrest during the struggle against apartheid. South Africa is characterised by tightly controlled input markets which together with the social and economic implications of the past political regime have resulted in an unemployment rate of 30 percent.

In addition the reintroduction of South Africa to the international stage brought about a tremendous increase in incidence of drug trafficking, vehicle theft, and hijacking, many of which can be linked to organised crime syndicates that have been found operating within the country (Brown, 2001). Loopholes in the border control system exist and the relatively easy trafficking of contraband across South Africa's borders is notoriously well known (SAPS, 1996).

Currently South Africa is crippled by crime which seems unlikely to abate within the near future. Private security has become one of the most profitable industries 
employing well over 450000 people (Brown, 2001). Many suburban South Africans live in jail-like homes guarded by vicious dogs, razor wire, and armed security guards summoned by panic buttons.

Region-specific and demographically representative monitoring of crime only began after the democratically elected government came to power in 1994 . The introduction of these statistics has made it apparent that something had to be done to control crime in South Africa. In 1994 Interpol ranked South Africa as the second most dangerous country in the world with more than 60 murders per day compared to the rate of 9 in the United States and an international average of 5.5. It was also ranked as second in the world with respect to sex related crimes and had the highest number of rape cases reported (141 cases per day) (Builta, 1995).

The study of the crime rate in South Africa is relevant from a national and international perspective. Within South Africa basic elements of human rights such as freedom of movement, personal security, the preservation of human dignity and in the final instance the very right to life, have been continually jeopardised by the effects of violent crimes and have traumatised the majority of the population. In fact the results of a survey indicate that as many as 25 percent of South African households have experienced some form of crime directly (Brown, 2001). This has created a sense of anxiety and apprehension within the population.

It is clear that the crime rate has also contributed to the loss of professionally skilled people if one accepts the official reasons that have been provided for emigration. The cost of crime to the insurance industry amounts to approximately 35 per cent of all insurance claims paid out. These costs mentioned represent only some of the direct financial costs associated with crime, they do not include the indirect costs associated with crime. Indirect crime related costs such as those costs associated with the criminal justice process, medical costs, and loss of working hours are not included (SAPS, 1996).

Internationally the crime rate has a negative influence on investor confidence and consequently South Africa has been unable to attract the quantities of foreign direct investment it requires to attain the growth rate to enable it to address the inequities of the past, secure sustainable developmental programmes and focus on new national issues affecting the country such as managing the Aids pandemic. The long-term survival of the economy relies on South Africa being able to take a position equal to its peers in the global economic environment as a stable and reliable trade partner. Apart from the government and private investment required in order to help alleviate the backlog of social problems extensive long-term foreign direct investment is also essential (Abedian \& Cronje, 1995). 
A need therefore exists for an intensive study into the nature and causes of the crime rate in South Africa so that the correct policies can be put into place in order to control this serious socio-economic problem and barrier to long term economic growth and prosperity. The aim of this study will be to determine the significance and magnitude of the impact of the social, economic and demographic variables that have been identified in the literature as possible determinants of crime in South Africa.

\section{THEORETICAL BACKGROUND}

Woman and girls in South Africa are increasingly victims of physical, sexual and psychological abuse irrespective of age, status, income, creed, colour or culture. Unemployed individuals accounted for 49 percent of the offenders of such crimes.

Violent crimes (murder and attempted murder), which cannot be separated from the business dealings associated with organised crime, and crimes related to the social fabric of South African society (both categories of assault and rape), tend to have higher incidence in (SAPS, 1996b):-

(i) areas experiencing a high rate of urbanisation with concomitant social problems like urban unemployment, informal settlements which are difficult to police, high levels of relative deprivation and expectations and the displacement of rural support and value structures by peer group pressure (e.g. the phenomenon of gangs). International and interregional migration further increases the problem of urban unemployment. It is estimated that around 1000 people migrate to Johannesburg every month looking for work. They usually become squatters and then apply for lowcost public housing which is very difficult to get (Builta, 1995).

(ii) property-related crimes that are associated with organised crime (syndicates involved in crimes like vehicle theft, commercial crime, and robbery with aggravating circumstances - including bank robberies, robbery of cash in transit and hijacking) seem to be more prevalent in Johannesburg and the areas surrounding it in the Gauteng Province.

(iii) rural areas historically associated with the phenomenon of alcohol abuse.

The South African government has made only infrequent mention of the crime problem and often seems to underplay its severity more often shifting the blame to the media for over-dramatising the crime situation. The modest real overall increase in government spending on the criminal justice system means that in order to increase the state's ability to come to grips with crime, reliance is, one hopes, being placed on better management and better-trained personnel than on 
frivolous spending. Expenditure by the three crime-related departments (Safety and Security, Justice, and Correctional Services) has increased from R12.047 billion in 1994/95 to R27.792 in 2000/01 - a nominal increase of 11 per cent per year over this time period. The need to provide for South Africa's rapidly increasing prison population has been accepted by the government, and thus the department of correctional services stands to benefit most. More reliance seems also to be placed on improving skills and support systems than on increasing personnel numbers, which may be a step in the right direction (Gastrow, 1998).

The cause of the high crime rate has been difficult to pinpoint. Past analyses have indicated that crime generally has multiple attributing elements such as, economic recessions, poverty and unemployment, the inefficient level of crime expenditure, the age structure of the population, and even social and moral degradation (Fajnzylber, Lederman \& Loayza, 2002). The demographics of the South African population are changing the age structure of criminals and according to Hess (1997) there has been a boom in the number of child convicts.

Crime perpetrated by individual criminals such as burglary of residential and business premises, common robbery, shoplifting, other theft and stock-theft, have been found to occur evenly around the country. The explanation for the broader, and even rural, prevalence of these crimes is that the single criminal tends more often to be motivated by need than by greed (or economic profits), whereas in the case of organised crime economic profits, and not need, seems to be the predominant motivating factor (SAPS, 1996abc). It is therefore implied that unfavourable socio-economic circumstances, especially urban unemployment resulting from rapid urbanisation, may contribute to a continued increase in crimes often motivated by individual need, whereas organised crime may be more inelastic to both the economic and political climate and thus cannot be expected to react significantly if economic and political inadequacies alone are addressed.

It has also been suggested that other reasons for the high levels of crime include; government inaction to the crime situation, the lack of sufficient police presence, inadequate police training, a corrupt police force, a faulty justice system, ending capital punishment, and even the police and prisons civil rights union. (Smith, 1997). There has been a widespread belief that government expenditure on total protection services has not been adequate given the current crime situation in South Africa. This line of thought is however based on the assumption that increased expenditure on total protection has a deterrent effect and is thus an important avenue for combating crime. 


\section{METHODOLOGY}

The study of crime in South Africa can be approached from many angles because of the widespread influence of crime on different spheres of society and everyday life. The economic model of crime focuses on the costs and benefits of crime, treating it as an alternative career or way of earning a living, in other words as a consumption model. This methodology assumes that rational choices are being made by rational individuals in order to calculate and compare the costs and benefits of illegal activities with non-criminal alternatives of earning a living. The expected benefits from crime tend to be the difference between the windfall and the opportunity cost of the crime, while the costs are given by the penalties imposed on apprehended criminals (Fajnzylber, Lederman \& Loayza, 2002). Usually such models would include both supply and demand variables which enter implicitly into an individual's decision making process.

An improvement to the economic model of crime involves an interdisciplinary approach which can include social, political, economic and law enforcement variables in its design. The focus of such an interdisciplinary model is broader than the economic model and includes other crime causation variables which may contain important information on the causes of crime. Variables normally included in the interdisciplinary model are the following (Brown, 2001):-

(i) clearance rate: Given a fixed manpower resource, the proportion of crimes that are cleared (the probability of apprehension) would be expected to be inversely related to the volume, and thus, to the rate of crime (Fox, 1978).

(ii) conviction rate: The number of people charged of a crime who are convicted for that crime would be expected to be negatively related to the crime rate (Avio \& Clark, 1976).

(iii) average sentence received: This can be seen as a deterrent to crime if sentences are severe and should thus have a negative effect on crime (Avio \& Clark, 1976).

(iv) value of stolen/damaged property or a proxy thereof: Can be seen as the payment for crimes such as theft. One would expect a positive relation with the crime rate (Becker, 1968).

(v) standard of living variable such as income per capita: This represents the opportunity costs of crime. Consequently, a negative relation to crime would be expected for this variable (Fajnzylber, Lederman \& Loayza, 2002).

(vi) unemployment rate: A macroeconomic variable associated with the general health of the economy and would be predicted to have a positive relation to crime.

(vii) education level would be expected to be negatively related to crime (Fajnzylber, Lederman \& Loayza, 2002). 
(viii) demographic indicators such as age distribution, and in particular the participation rate of those persons who are between the ages of 15 and 34, and a gender dummy variable - would both also be related to the crime rate (Shapiro \& Ahlburg, 1986).

(ix) other social, demographic, and economic indicators such as the number of citizens per police officer, racial group, number of people per household, home language, occupation, geographic location, consumer price index and gross domestic product could also be included in such a model and be expected to contribute to the crime rate (Schmidt \& Witte, 1984).

Data on these variables are usually used in a time series model in order to assess their relation to and effect on the crime rate. Models following the economic model tend to explain around 90 percent of the variation in the crime rate indicating that a significant proportion of the crime rate can be explained by such a model. A problem with the economic model of crime is its focus on the operation of the criminal justice system, which is severely limited with respect to crime causation theory (Brown, 2001). A further problem with models of this nature is that in order for them to work properly and yield significant results large time series of data are required. In general the conclusion derived from this approach are that crimes will be committed whenever the benefits of committing crimes exceed the possible costs associated with being apprehended, convicted, and punished for such crimes, and thus policy prescriptions usually focus on increasing the cost associated with criminal activity. One of the pioneering studies on crime by Becker (1968), using the economic model of crime, indicates that increasing the probability of being punished is the most effective way to reduce the crime rate.

With only 8 years of complete crime data available for South Africa, a reliable time-series regression model cannot be estimated due to insignificant degrees of freedom. However, these data are available for all nine provinces as well as for many of the socio-economic variables and thus a cross-provincial panel data model has been chosen for this analysis.

The longitudinal or panel data set follows fifteen crime types over time and thus provides many observations on each crime type in the sample. Panel data sets for economic research have the following advantages over both cross-sectional and time series data sets (Hsiao, 1999):-

(i) they contain a larger number of observations since they have both a crosssectional and time series component. This results in greater degrees of freedom and thus improves the efficiency of econometric estimates (Fourtin, Keil \& Symons, 2001). 
(ii) panel data sets allow the researcher to analyse more complicated behavioural models than either pure cross-sectional or pure time series data sets. Micro-dynamic and macro-dynamic effects cannot be estimated using cross-sectional data, while time series data cannot provide accurate estimates of dynamic coefficients.

(iii) one is better able to control for the effects of omitted variables by using information given by both the intertemporal dynamic and the individuality of the entities being investigated.

The fixed effects and random effects panel model specifications involve some form of aggregation and the assumption that the explanatory variables have identical impacts across crime types, and thus suffer from statistically biased results (Cherry \& List, 2002). The importance of the different explanatory variables tends to vary across different crimes because of the different 'skills' that are required for perpetrating different crimes. For example, to commit fraud, offenders are per definition employed, usually older than other criminals and also tend to be better educated and have higher incomes. In contrast, the effects of income, education, and age differ for those who are likely to commit malicious damage to property. This type of crime tends to be committed by offenders who are younger and for whom income represents a low opportunity cost because of their juvenile status (Foot \& Stoffman, 1998). It is assumed that due to the different 'skills' required for each crime type the resultant coefficients would be significantly different so that pooling data in any form would be inappropriate in this case. Consequently the appropriate estimation model to be used in this study is a seemingly unrelated regression (SUR) model in which a different set of crime equations are estimated with different coefficients for each of the equations. This technique captures estimation efficiency due to the correlation of errors across the different equations.

\section{DATA ANALYSIS}

The statistics on the 15 crime types (fraud, forgery and misappropriations, malicious damage to property, arson, common assault, rape and attempted rape, common robbery, attempted murder, murder, theft out of motor vehicles, theft of motor vehicles, shoplifting, stock theft, burglary from residential premises, bank robbery and carjacking) were collected for the months of January to September for the years 1994 to 2001 for all nine South African provinces (Northern Cape, Eastern Cape, Western Cape, Free State, Gauteng, Kwazulu-Natal, Mpumalunga, North West and Limpopo) and include the total number of transgressions over this period as well as the respective crime ratios calculated per 100000 of the population. 
The decision to use provincial data was based on data availability, as there was not enough national time series data available to construct a national time series model of crime. Taking data for the nine provinces added significant degrees of freedom to the model and a substantial amount of additional variance in variables that are specific to a particular province and are thought to influence the crime rate. Consequently, by using provincial data, there is scope for improving estimation efficiency and the power of statistical tests significantly.

Data on 15 crime types were collected over an 8-year period resulting in a data set of 120 observations for each of the 9 provinces. The 9 provincial data sets were then stacked to provide the final data set defined across the 15 crime types and over 72 observations ( 9 provinces for 8 years), resulting in a panel that should contain 1080 elements. However for two of the crime types (carjacking and bank robbery) data for 1994 and 1995 is unavailable, and thus 36 elements ( 2 years for 2 crime types for 9 provinces) have been excluded from this data set, hence the classification of the model as an unbalanced panel data model. The final data set therefore contains a total of 1044 observations. This stacked specification of the data was possible due to the fact that since all variables are ratios the data used is assumed stationary, and only stationary data can be pooled in this manner. Another advantage of employing ratios is that the growth rate of the population figures are neutralised. By using ratios artificial increases in the crime rate due to population growth, and not to a real increase in the incidence of crime, are avoided. Ratios also enable one to compare the incidence of crime among different provinces or countries, notwithstanding differences pertaining to the size of populations. Furthermore, comparisons involving ratios are also more appropriate than comparisons involving frequencies, as ratios generally indicate:-

(i) the probability of becoming a victim of a specific crime.

(ii) the presence of those factors, or combinations of factors, conducive to the incidence of specific crimes and which have to be addressed in order to combat these crimes effectively.

The data was converted to logarithmic form in order to be able to interpret the resulting coefficients as elasticities.

The expenditure on total protection services as a percent of gross domestic product variable and the proportion of the population that is male and between the ages of 15 and 34 years variable are both national variables and were collected from the Budget Review and Census Report respectively. Data on the remaining explanatory variables was collected from various issues of the October Household Survey and the Labour Force Survey. These variables are all specific to a particular province. 
The fact that crime in South Africa is on the increase, or at best stable at a very high level, cannot be debated; however, the rate at which some crimes seems to have been growing can be brought into question. There are two reasons why there may be errors in these data. Firstly, accurate and region-specific (the nine new provinces) monitoring of crime only began after the democratically elected government came to power in 1994. Up until that point in time crime statistics were available largely for minority areas only, whereas the crimes committed to the majority of the population were left, either unreported, badly documented and generally ignored by the government of the day. Secondly, in traditionally black communities where crime rates are higher than in other areas, there is still a distrust of the police and vigilante justice is still common. However, initiatives have been set in place to encourage crime reporting such as implementing a crime prevention campaign which calls on people to report crime, increasing awareness of crime and improving police availability. These have both resulted in a significant increase in the number of crimes reported, without crimes themselves necessarily having increased.

We need to take a closer look at all the variables included in this model, by classifying them into economic, demographic and socio-economic variables.

\subsection{Economic variables}

(i) Income per capita: If crimes are motivated by need as opposed to greed, one would expect that there would be some relation between income per capita and the crime rate. Generally one would expect a negative relation since greater income per capita represents a higher opportunity cost of committing crime, and consequently one would expect a lower crime rate (Brown, 2001). However, the income per capita variable does not take account of the distribution of income. It may be that the income of small proportion of the population increase by amounts large enough to affect overall income per capita leaving the income of the majority of people unchanged or even lower than before. A study by Fajnzylber et al. (2002) found that income inequality was a robust determinant of violent crimes. In this case one could even expect a positive relation between crime and income, since an increase in income per capita represents a larger possible reward to criminal activity.

(ii) Unemployment rate: Generally there are two main ways of securing an income, either through legal job markets or illegal activities. The bulk of the literature suggests that if the official unemployment rate is high then there is a certain incentive to switch to illegal activities to earn a living, and thus it is to be expected that there is a positive relationship between the level of unemployment and the crime rate. 
(iii) Expenditure on total protection services: Total protection services consist of three main national expenditure items; safety and security, justice and correctional services. Theory suggests that increased expenditure on these three items would generally increase the probability that perpetrators of crimes are caught, successfully sentenced, and finally punished. This increases the risk of criminal behaviour and thus requires an equal increase in return, which if not forthcoming make criminal activities less attractive relative to legal means of earning an income. It is thus expected that increasing expenditure on total protection services would lead to a subsequent decline in the crime rate. Other law enforcement variables, as given by the economic model of crime, are not available and thus expenditure on law enforcement was taken as a proxy for these variables.

(iv) Growth rate of GDP: This variable would take the phase of the business cycle into account. It is expected that a growing economy, and thus a positive growth in GDP value, would be associated with a decrease in the crime rate, since in an expanding economy the opportunity cost of crime increases.

\subsection{Demographic variables}

(i) Degree of urbanisation: Urbanization is generally related to higher levels of criminal activity and thus in this study a positive relation is expected between urbanization and the crime rate. Urbanization concentrates large numbers of people and wealth in a relatively small area thus providing increased opportunities for criminal activity.

(ii) Proportion of the population that is male and aged 15 to 34 years of age: From studies such as Avio and Clark (1976), and more recently Foot and Stoffman (1998), one can conclude that the majority of crimes are committed by males aged between 15 and 34 years of age. This implies that the larger the size of this cohort is in any given population, the higher the crime rate should be. In other words a positive relationship is expected between this cohort size and the crime rate. This variable is believed to decrease the moral cost of committing crime and increase the net earnings from illegitimate activities, resulting in a higher crime rate (Brown, 2001).

(iii) Economically active proportion of the population: The economically active portion of the population is defined as all those people between the ages of 16 and 65 years of age who are able to work. The sign of this variable is generally expected to be negative if it is assumed that there are enough jobs available to absorb these economically active people and that there will be ample legitimate employment opportunities available. If, however, there are not enough jobs available to accommodate the economically active portion of the population then criminal or illegal 
alternatives of making money may be pursued and a positive coefficient can be expected.

\subsection{Social factors}

(i) Ratio of woman to men: It is assumed that men commit the majority of crimes. The larger the ratio of woman to men in any community would thus be expected to reduce the relative crime rate in that community since the proportion of those committing crime is relatively reduced. This variable may also capture some positive ethical or moral effects introduced through the presence of a larger ratio of woman to men in any community. This variable is assumed to increase the moral cost of committing cri-me and should thus lead to a lower crime rate.

(ii) Number of drug possession offences: This variable measures the effects that drugs and alcohol have on the crime rate. It is expected that an increased consumption of alcohol and drugs are related to higher crime rates since use of these substances impairs the correct assessment of the risks and rewards associated with committing a crime and may also introduce a temporary departure from the assumption that criminals are rational when deciding on committing crimes.

(iii) Education. This variable is measured by the proportion of all learners that pass the senior certificate examination. It is expected that this variable would be negatively related to the crime rate since greater educational levels create more legitimate income earning opportunities.

\section{EMPIRICAL ESTIMATION}

We estimate a crime equation of the following form $c_{i t}=\alpha_{i}+\beta_{i} \mathrm{x}_{i t}+\varepsilon_{i t}$ with 1044 observations on the 15 crime types, across the 9 provinces for the 8 year period of 1994 to 2001 . There are a total of 9 regressors: the constant and 8 explanatory variables included in $\mathrm{x}_{\mathrm{it}}$. The eight explanatory variables are those discussed in the previous section of this paper.

\subsection{Econometric Results}

The R-square value for the interdisciplinary SUR model has a value of 0.953 , which indicates that over 95 per cent of the variation of the overall crime dependent variable can be explained by the variation of the eight independent variables. This confirms that the estimated model fits the data well. We will now take a more detailed statistical and economical look at the results achieved for each of the eight independent variables as explanatory variables of the fifteen 
individual crime types. Both the education and change in GDP variables yielded insignificant results and were excluded from the final model design. Educational attainment was also found to be insignificant in the study by Fajnzylber, Lederman and Loayza (2002).

\subsection{Interpretation of Results}

\subsubsection{Economic variables}

(i) Income per capita: According to the results in Table 1 the income per capita variable was found to be statistically significant for all crime types. For twelve of the crime types the null hypothesis of an insignificant coefficient was rejected at the 1 per cent level of significance, while for the remaining three crime types this hypothesis was rejected at the 10 per cent level of significance. This means that income per capita is an important explanatory variable for all crime types and should therefore be included in the crime model.

Income per capita has a positive impact on the majority of crimes. This can be explained by the fact that criminal activity is a substitute for legitimate employment especially in the case where there is an unequal distribution of income. Thus, even though income per capita shows an increasing trend over time it is possible that this results as a consequence of large increases in income for a wealthy minority, while the incomes of the majority of people remain constant or even decrease. In this case an increase in income per capita would represent a larger reward for criminal activity and thus the amount of such activity could be expected to increase.

Stock theft, rape and attempted rape, and common assault all have negative coefficients suggesting that an increase in income would lead to decrease in these crime rates. The negative coefficient for stock theft can be easily explained but the case for rape and common assault initially appear less convincing. In the case of common assault, there are two possible explanations for the negative coefficient. Firstly, higher income may reduce the levels of social tension and stress making people less likely to commit acts of assault or, alternatively, that there is not a great incentive to report such crimes and thus the data series may be unreliable. 


\begin{tabular}{|c|c|c|c|c|c|c|c|c|}
\hline 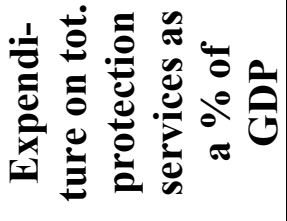 & 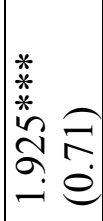 & $\begin{array}{ll}* \\
* \\
* & \overparen{7} \\
& \tilde{n} \\
i & e\end{array}$ & 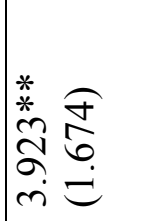 & 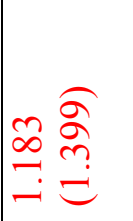 & 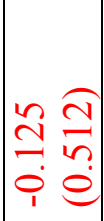 & $\begin{array}{ll}* & \\
* & \\
* & 0 \\
\cdots & 0 \\
& \vdots \\
- & e\end{array}$ & $\begin{array}{ll}0 & 0 \\
m & i n \\
0 & 0\end{array}$ & 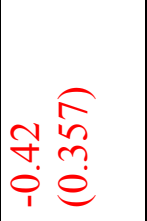 \\
\hline 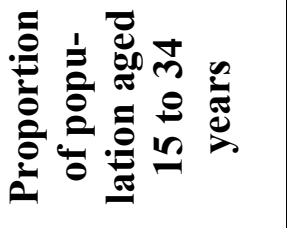 & 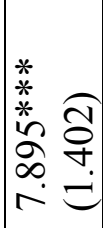 & \begin{tabular}{ll}
$*$ & $*$ \\
$*$ & $\infty$ \\
$m$ & 0 \\
\hdashline & 0 \\
$i$ & $\vdots$
\end{tabular} & 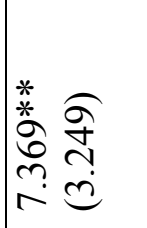 & 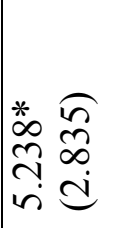 & 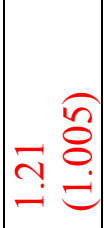 & 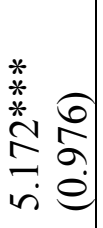 & 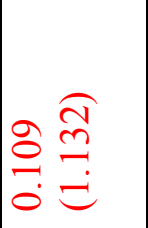 & $\begin{array}{ll}m & \widehat{I} \\
0 & \hat{\sigma} \\
0 & 0 \\
\dot{1} & 0\end{array}$ \\
\hline 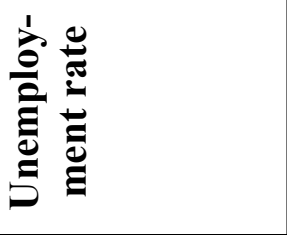 & 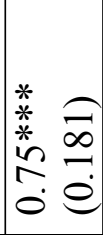 & 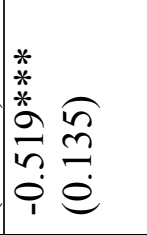 & 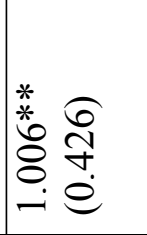 & 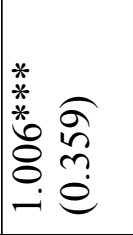 & 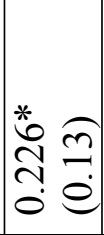 & 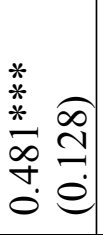 & $\begin{array}{l}\approx \underset{+}{ \pm} \\
\Xi \dot{0}\end{array}$ & $\begin{array}{ll}\hat{\imath} & \widehat{\partial} \\
0 & 0 \\
0 & 0 \\
1 & 0\end{array}$ \\
\hline 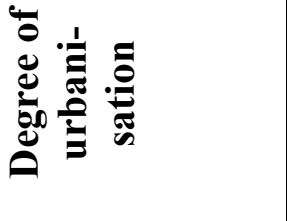 & 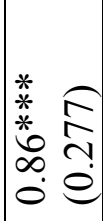 & 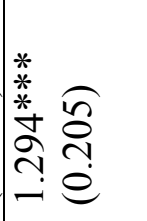 & 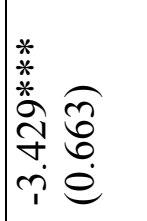 & $\begin{array}{ll}* & \\
* & \widehat{N} \\
\hat{N} & \hat{n} \\
\infty & n \\
n & 0 \\
- & e\end{array}$ & 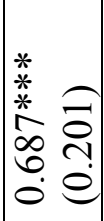 & 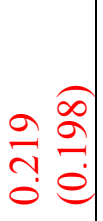 & 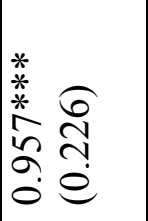 & 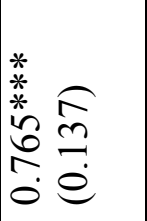 \\
\hline 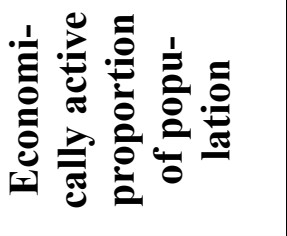 & 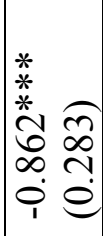 & 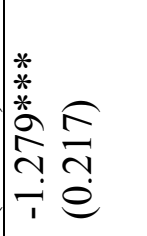 & 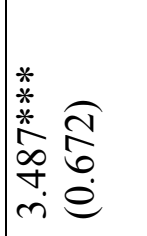 & 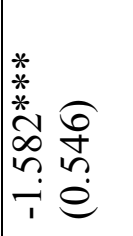 & 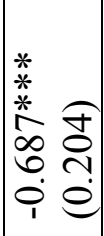 & 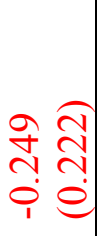 & 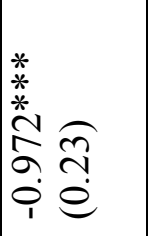 & 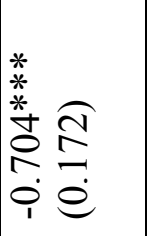 \\
\hline 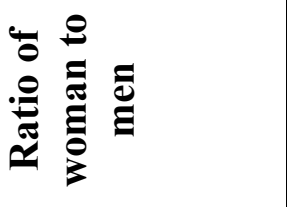 & $\begin{array}{ll}* & \\
* & \sigma \\
* & 0 \\
\sigma & \infty \\
\dot{\tau} & 0 \\
\dot{r} & 0\end{array}$ & 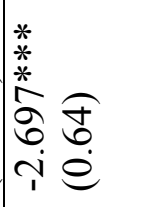 & 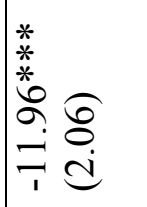 & $\begin{array}{ll}* & \sigma \\
* & \sigma \\
m & \vdots \\
m & =\end{array}$ & 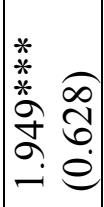 & $\begin{array}{ll}* & \\
* & \infty \\
\tilde{b} & 0 \\
& \vdots \\
ن & 0\end{array}$ & 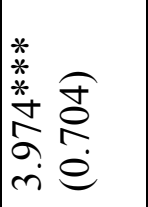 & \begin{tabular}{ll}
$\stackrel{*}{*}$ \\
$\stackrel{*}{*}$ & $\overparen{9}$ \\
$\stackrel{9}{+}$ \\
\hdashline & $\dot{1}$ \\
\hdashline & 0
\end{tabular} \\
\hline 車总 & \begin{tabular}{ll}
$*$ & 0 \\
$*$ & 0 \\
0 & 5 \\
\multirow{0}{*}{} & 0 \\
0 & 0
\end{tabular} & 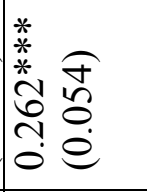 & 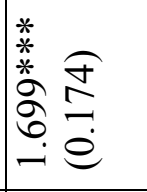 & 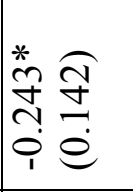 & 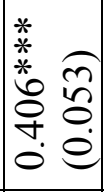 & 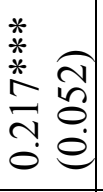 & 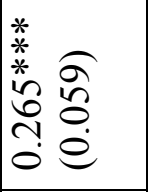 & 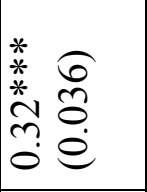 \\
\hline 异 ప & $\begin{array}{ll}* & \\
* & 0 \\
\infty & \infty \\
2 & = \\
i & 0 \\
0 & 0\end{array}$ & 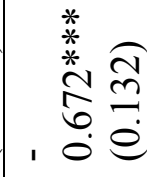 & 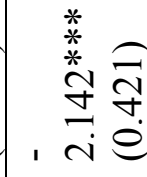 & 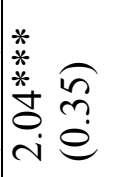 & 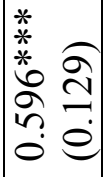 & 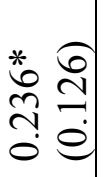 & 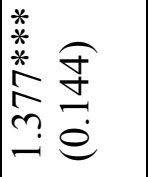 & $\begin{array}{ll}* & \widehat{\alpha} \\
\hat{n} & \infty \\
0 & 0 \\
\dot{0} & 0\end{array}$ \\
\hline 方莒 & $\begin{array}{l}\text { ते } \\
\infty \\
+ \\
+\end{array}$ & ণิ & $\begin{array}{l}0 \\
1 \\
\infty \\
\infty \\
1\end{array}$ & 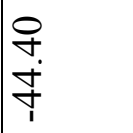 & $\begin{array}{l}\infty \\
0 \\
0 \\
0 \\
1\end{array}$ & $\begin{array}{c}\infty \\
ָ \\
\\
\end{array}$ & $\begin{array}{l}\infty \\
\infty \\
\infty \\
\end{array}$ & $\stackrel{n}{\stackrel{n}{n}}$ \\
\hline 芯 & $\frac{\dot{\bar{\theta}}}{\stackrel{\Xi}{\Xi}}$ & 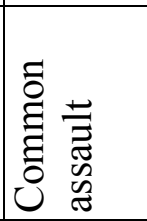 & 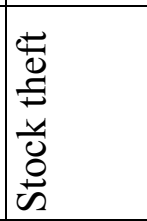 & 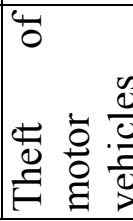 & 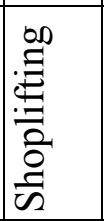 & $\begin{array}{l}\tilde{0} \\
\text { 安 } \\
\end{array}$ & 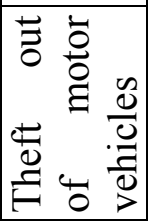 & 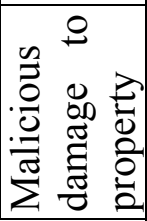 \\
\hline
\end{tabular}




\begin{tabular}{|c|c|c|c|c|c|c|c|c|}
\hline 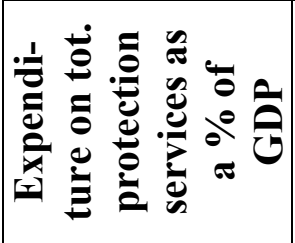 & 疍 & 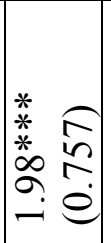 & 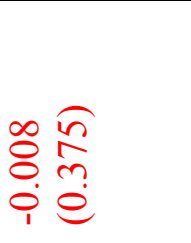 & $\begin{array}{ll}n & \widehat{\hat{\sigma}} \\
\hat{+} & 0 \\
\dot{0} & \tilde{e}\end{array}$ & 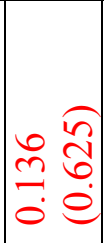 & 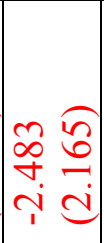 & 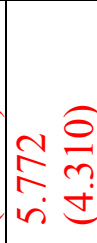 & 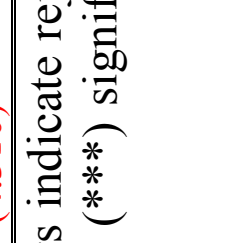 \\
\hline 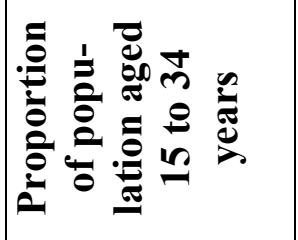 & 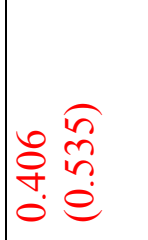 & 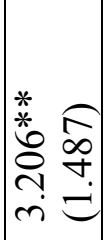 & 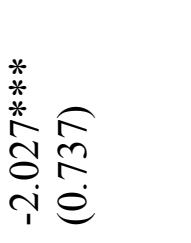 & 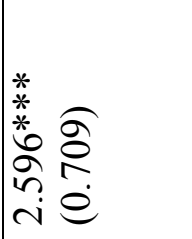 & 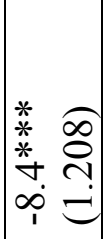 & 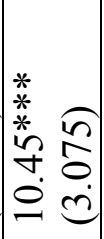 & $\begin{array}{ll}0 & \frac{m}{n} \\
0 & \frac{n}{n} \\
\infty & 0\end{array}$ & 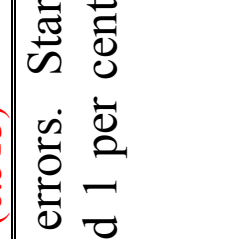 \\
\hline 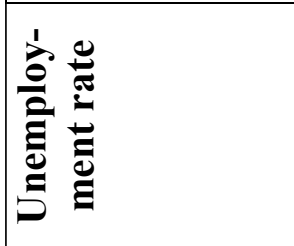 & 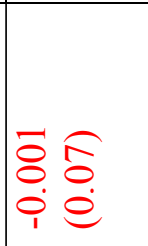 & $\begin{array}{ll}* & \widehat{2} \\
* & 0 \\
\dot{*} & 0 \\
0 & 0\end{array}$ & $\begin{array}{ll}0 & 0 \\
0 & 0 \\
0 & 0 \\
0 & 0 \\
0 & 0\end{array}$ & 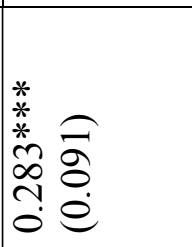 & \begin{tabular}{ll}
$\infty$ & 0 \\
0 & 0 \\
\hdashline & $n$ \\
0 & 0 \\
& 0
\end{tabular} & 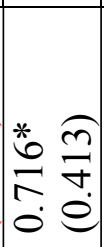 & $\begin{array}{ll}* & \\
* & 0 \\
\infty & 0 \\
\infty & \infty \\
- & 0\end{array}$ & 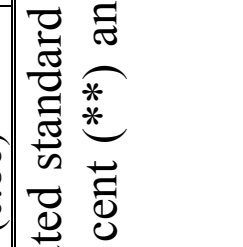 \\
\hline 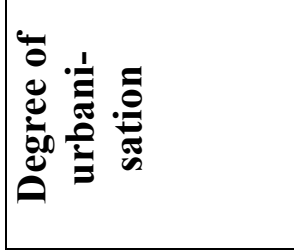 & 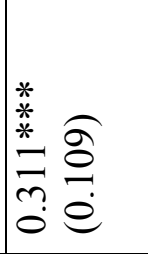 & 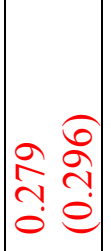 & 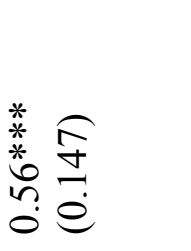 & $\begin{array}{ll}* & * \\
* & \infty \\
\infty & \infty \\
\mathbb{1} & \ddots \\
0 & 0 \\
- & \varrho\end{array}$ & 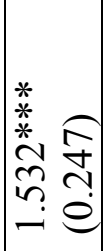 & & ণิ & 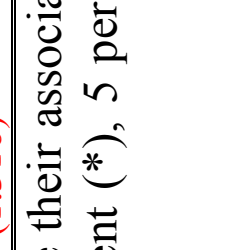 \\
\hline 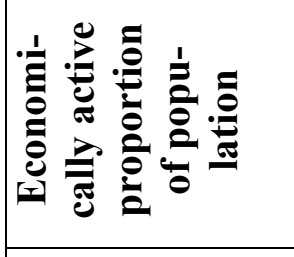 & 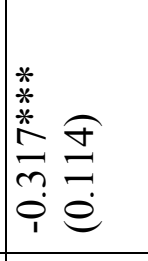 & \begin{tabular}{cc|} 
& \\
1 & 0 \\
0 & 0 \\
$n$ & 0 \\
0 & 0 \\
1 & 0
\end{tabular} & 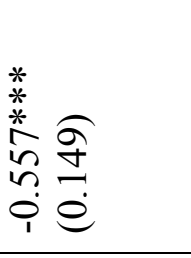 & 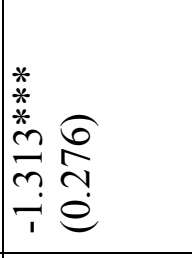 & 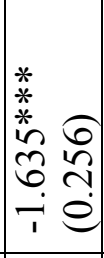 & $\begin{array}{ll}0 & \\
\infty & \approx \\
0 & 0 \\
0 & 0 \\
0 & 0 \\
1 & \ddots\end{array}$ & $\begin{array}{ll}n & \infty \\
6 & = \\
i & 0 \\
i & 0\end{array}$ & 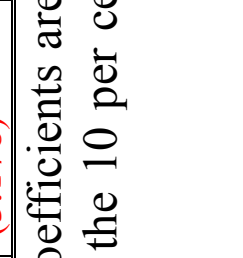 \\
\hline 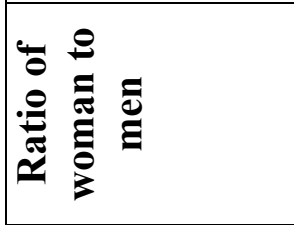 & 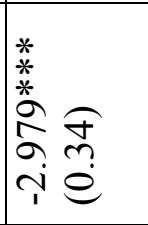 & 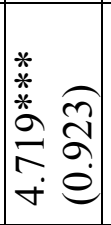 & 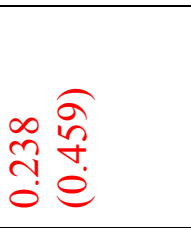 & 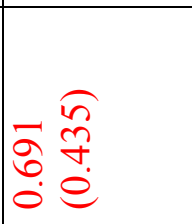 & 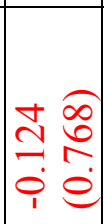 & $\begin{array}{cc}\vec{m} & \widehat{\sigma} \\
\tilde{n} & \infty \\
0 & - \\
1 & =\end{array}$ & 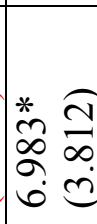 & 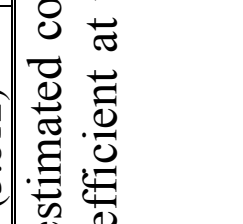 \\
\hline 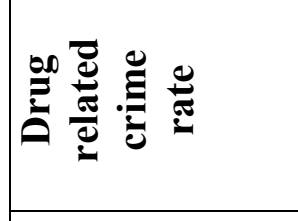 & $\begin{array}{ll}* & \\
* & 0 \\
* & \infty \\
0 & 0 \\
0 & 0 \\
0 & 0 \\
0\end{array}$ & $\begin{array}{cc} & \\
- & \infty \\
8 & 0 \\
0 & 0 \\
0 & 0\end{array}$ & 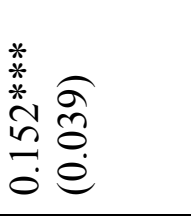 & $\begin{array}{ll}1 & \infty \\
n & 0 \\
0 & 0 \\
0 & 0\end{array}$ & $\begin{array}{ll}\infty & 0 \\
0 & 0 \\
0 & 0 \\
0 & 0 \\
1 & 0 \\
1 & 0\end{array}$ & 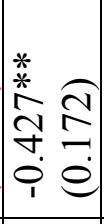 & 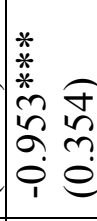 & 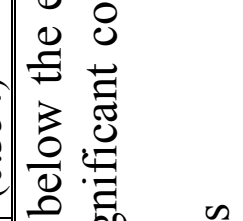 \\
\hline 异 & 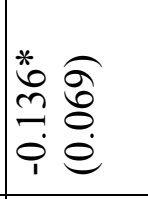 & 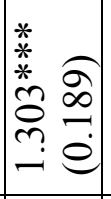 & 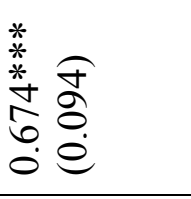 & 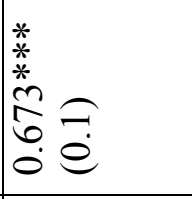 & 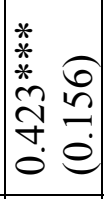 & 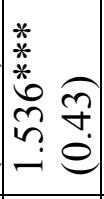 & $\begin{array}{ll}* & \\
* & 0 \\
* & \infty \\
0 & \infty \\
\dot{0} & 0\end{array}$ & 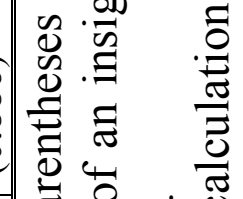 \\
\hline 竎莒 & $\begin{array}{l}\stackrel{0}{7} \\
\text { ஸે }\end{array}$ & $\frac{\dot{\Xi}}{\vec{r}}$ & r. & $\begin{array}{l}\hat{b} \\
\dot{+} \\
\end{array}$ & $\frac{f}{\dot{f}}$ & $\frac{a}{n}$ & $\begin{array}{l}\text { W } \\
\dot{+} \\
\infty \\
1\end{array}$ & 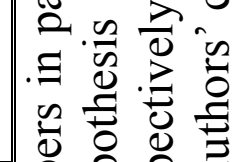 \\
\hline 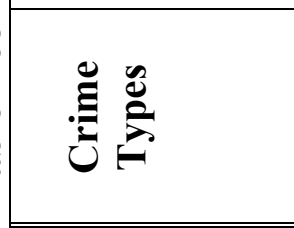 & 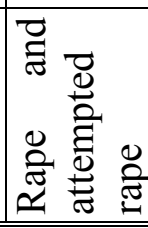 & 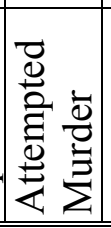 & 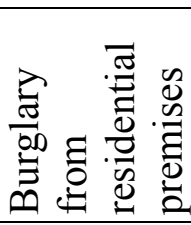 & 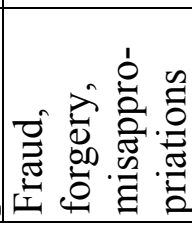 & 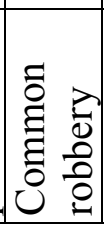 & 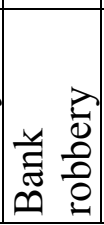 & 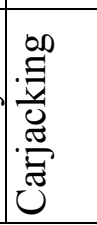 & 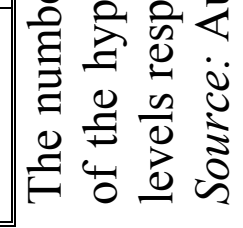 \\
\hline
\end{tabular}


A possible explanation of the negative coefficient for rape may be the fact that often rape goes hand in hand with other crime types that are perpetrated in order to gain materially, such as burglary of residences and common robbery. Consequently any increases in income is likely to decreases the need for committing materially motivated crimes and thus incidence of rape may decrease too.

(ii) Unemployment rate: The coefficients of ten crime types reject the hypothesis of an insignificant coefficient at various levels of statistical significance, indicating that the unemployment rate should be included as an explanatory variable in these cases. In general one would expect a positive relationship between the unemployment rate and the crime rate since higher levels of unemployment indicate that there are fewer legal opportunities of employment available, and thus the unemployed may have to turn to illegal or criminal means of earning income. From Table 1 one can see that this is in fact so for nine of the ten crimes for which unemployment is a significant explanatory variable. However, for the case of common assault the coefficient has a negative sign indicating that increases in unemployment are related to a decrease in incidence of common assault. Again a possible explanation for this could be that because of the lack of any material reward such crimes are not consistently reported and this could lead to the data giving spurious results.

(iii) Expenditure on total protection services: For only five crime types could the hypothesis of an insignificant coefficient be rejected, in four of these cases at a 1 per cent level of significance and in the fifth case at the 5 per cent level of significance. In other words for the remaining ten crime types the hypothesis that the coefficients are insignificant could not be rejected indicating that for these crimes this variable is not a significant explanatory variable for the variation on the dependent variable. The disappointing results obtained for this variable could possibly be explained by the fact that national figures were used as a proxy for the expenditure across all provinces and was thus not defined on a provincial basis. It is common knowledge, however, that expenditure on the three components of total protection services differs vastly across the nine provinces and this variation is not included in this variable.

Theory dictates that there should be a negative relationship between expenditure on protection and the crime rate since the probabilities of being caught, tried and punished generally increase, and with it the risk of committing crimes also increases. The incidents of criminal activities will then decrease if it is assumed that the rewards from committing these 
crimes remains constant or even increases, but at a lower rate than the risks thereof. This appears to hold true for only one of the crime types, common assault. For the other crimes, a significant positive relation exists indicating that increases in protection expenditure result in higher incidence of crime. A possible explanation for this positive relationship is that there may exist a threshold level of protection expenditure above which the negative relation holds, but below which may have any sign. South Africa may not have reached this threshold level of expenditure yet and thus increases in expenditure have no deterrent effect on the crime rate. It may also be the case that the level of expenditure actually adjusts to the crime rate in which case a higher crime rate would cause expenditure on protection to increase, hence the positive sign for many of these coefficients. Corruption and possible government inefficiencies may also add to the conflicting results associated with the results of the coefficients of this variable.

\subsubsection{Demographic variables}

(i) Degree of urbanisation: For eleven of the fifteen crime types this variable is highly significant and the hypothesis of insignificant coefficients is rejected at a 1 per cent level of significance in all of these cases indicating that this variable is a good explanatory variable for the variation of the dependent variable. As mentioned earlier, a positive relationship is expected between this variable and the crime rate. This is so because as relatively more people move to urban areas there is a resultant increase in both the concentration of people and wealth within a relatively confined area. At the same time the large numbers of people have to compete against one another for employment and costs generally tend to be higher than rural areas, which increase the amount of income required for sustainability. There is consequently a large incentive to earn income from illegal means. Crimes that are generally not committed for material gain also tend to be higher in urban areas due to the increased levels of social pressure and the large diversity of people living in urban areas. From the model output it is clear that for all crime types, except for stock theft, this positive relationship is in fact upheld as is expected. Stock theft tends to occur mainly in less populated rural areas and thus the negative coefficient for this variable is also justified by the fact that relatively more people living in urban areas implies that relatively fewer people are living in rural areas, and thus incidence of stock theft would be expected to increase, given that the probability of being caught is reduced together with the rural population. 
(ii) Proportion of the population that is male and aged 15 to 34 years of age: For ten of the crime types the parameter nullity hypothesis can be rejected. For ten crime types this variable has a significant impact at least at a 10 per cent level of significance. Since the majority of crimes are perpetrated by young men aged between 15 and 34 years of age one would expect that an increase in the size of this cohort would lead to an increase in the crime rate. From the results of the model one can see that there is in fact a positive relationship for seven of the crime types as expected. The remaining coefficients have a negative sign indicating an inverse relation between this variable and the crime rate. Again common assault has an unexpected sign, and again the explanation for this is that the data for this crime type may be incomplete or corrupt due to the low incentive to report incidence of such crimes. Burglary from residential property and common robbery also exhibit inverse relationships between this variable and their crime rates. Possible explanations for this negative relation is that perpetrators of such crimes are actually outside of this demographic cohort, since younger people generally have a size advantage over older people which gives them a comparative advantage when compared to older and larger people. Evidence of the very young cohort (younger than 15 years of age) being involved in crime is provided in Brown (2001). It may also be the case that much of the theft from residences may be committed by, or with the help of domestic employees, which also may fall out of the top end of this demographic.

(iii) Economically active proportion of the population: Eleven of the coefficients were found to be highly significant with the insignificant coefficient hypothesis being rejected at the 1 per cent level of significance for all of these cases. Ten of these coefficients have a negative sign suggesting that the larger the economically active proportion of the population, the lower the crime rate. Again the exception to this is stock theft where a positive sign for the coefficient is observed. This can be explained by the fact that economically active people would generally be pulled away from rural areas where employment opportunities are relatively scarce, to urban areas where employment opportunities are more promising.

\subsubsection{Social factors}

(i) Ratio of woman to men: For eleven of the crime types the insignificant coefficient hypothesis could be rejected in favour of the alternative hypothesis indicating that this variable is a statistically significant variable and thus should be included in the model of crime. A negative relationship is expected for the coefficient of this variable since the more 
women relative to men generally can be expected to lead to lower crime rates for most crime types. In four cases this is in fact so, however for the remaining seven crime types a positive relation was found to exist between this variable and the crime rate. There are a few possible reasons for this positive relationship. Firstly, it may be that for certain crime types such as shoplifting, women are as guilty of committing these crimes as men in which case a positive relationship would be justified. The second possible explanation for the positive relationship is that women generally make soft targets for many crime types and thus any areas where there are relatively more women then men one could expect more crimes against or involving women.

(ii) Number of drug possession offences: For twelve of the fifteen crimes this variable was found to be a statistical significant and the hypothesis of insignificant coefficients could be rejected generally at the 1 per cent level of significance. One would expect that this variable be positively related to incidence of crime and for nine of the crime types this is the case. For the remaining three crimes: bank robbery, carjacking and theft of motor vehicles a negative coefficient was found. This can be explained by the fact that generally these three crimes require a higher level of cognitive functioning and may have been planned in great detail prior to the crime actually being committed. Any use of alcohol or drugs will impair the cognitive functioning and thus the probability of success in executing their crimes.

\section{CONCLUSION}

The panel data study of crime across the provinces of South Africa provides strong evidence in favour of an interdisciplinary model of criminal behaviour that emphasizes the role of economic, social and demographic variables in its design. The crime rate in South Africa has a far broader range of causes than those specified in the economic model of crime, and therefore emphasis on this model alone may only be able to explain a limited share of the crime problem.

The most significant explanatory variables of the crime rate are income per capita, unemployment rate, degree of urbanisation, ratio of woman to men and drug possession offences respectively. These variables indicate that the main motive for criminal behaviour in South Africa is need and not economic profit. This result suggests that the long term management and reduction in the crime rate is primarily associated with the economic and social environment within the country since increases in these variables tend to raise the opportunity cost of 
criminal activities thus decreasing the returns to such activities and encouraging more legitimate behaviour.

According to the results obtained the expenditure on total protection tends to be the least important determinant of the crime rate. There are a number of possible explanations for this result. Firstly, the relationship may be non linear with a positive relation between the variables being found up to some critical or threshold level of expenditure and after which any further increases in expenditure would yield a negative relationship to crime. Secondly, since national expenditure data were used for this variable the data may contain spurious information resulting from aggregation bias. Provincial specific data may yield more robust results. Finally, this may not be a significant determinant variable of the crime rate in South Africa due to the fact that although expenditure increases over time law enforcement personnel may be inefficient due to the lack of adequate training and thus actual crime prevention may be minimally impacted. Focus on this variable should thus be on the improvement in the quality of the law enforcement and policing personnel and not only on the quantity thereof.

It can therefore be concluded that responsibility for combating crime lies not only in the hands of the department of justice and its focus on the criminal justice system, but also with most other governmental departments whose responsibilities include the reduction of unemployment and the improvement of economic and social conditions for more South Africans. According to the finding of this study the crime rate will be most efficiently controlled by addressing those issues that have the greatest impact on the choices available to the majority of South Africans in terms of employment and income earning opportunities. These choices are increased with greater education and employment opportunities, as well as with improvements in the basic developmental necessities required to attain a simple yet dignified standard of living.

\section{REFERENCES}

1 ABEDIAN, I. \& CRONJE, A. (1995) "Government foreign borrowing in South Africa", The South African Journal of Economics, 63(2): 132-47.

2 AVIO, K.L. \& CLARK, C.S. (1976) Property Crime in Canada: An Econometric Study, Ontario Economic Council: Toronto.

3 BECKER, G.S. (1968) "Crime and punishment: an economic approach", Journal of Political Economy, 76: 169-217.

4 BROWN, K.V. (2001) "The determinants of crime in South Africa", The South African Journal of Economics, 69: 2. 
5 BUILTA, J. (1995) South Africa: Crime is on the Increase. On-line at the Office of International Criminal Justice: http//www.acsp.uic.edu/oicj/ pubs/cje/060101.htm.

6 CHERRY, T.L. \& LIST, J.A. (2002) "Aggregation bias in the economic model of crime", Economic Letters, 75: 81-86.

7 FAJNZYLBER, P., LEDERMAN, D. \& LOAYZA, N. (2002) "What causes violent crime?" European Economic Review, 46.

8 FOOT, D.K. \& STOFFMAN, D. (1998) Boom, Bust \& Echo 2000: Profiting from the Demographic Shift in the New Millennium, Macfarlane, Walter and Ross: Toronto.

9 FORTIN, P., KEIL, M. \& SYMONS, J. (2001) "The sources of unemployment in Canada, 1967-91: Evidence from a panel of regions and demographic groups", Oxford Economic Papers, 53.

10 FOX, J.A. (1978) Forecasting Crime Data, Lexington Books: Toronto.

11 GASTROW, P. (1998) Parliament and Crime Issues: Recent events. Online at: http://www.iss.co.za.

12 HESS, S. (1997) "Boom in child convicts", Electronic Mail \& Gardian, July 4, On-line at http://www.mg.co.za.mg/news/97jul1/4.

13 HSIAO, C. (1999) "Analysis of panel data", Econometric Society Monographs No.11, Cambridge University Press.

14 OCTOBER HOUSEHOLD SURVEY P0317 (Various editions) Statistics South Africa.

15 SCHAPIRO, M.O. \& AHLBURG, D.A. (1986) "Why crime is down", American Demographics, October, 8(10): 56-59.

16 SCHMIDT, P. \& WITTE, A.D. (1984) An Economic Analysis of Crime and Justice: Theory, Methods, and Applications, Academic Press, Inc.: Toronto.

17 SMITH, N. (1997) "A state of emergency won't end crime", Electronic Mail \& Guardian, May 21, On-line at http://www.mg.co.za.mg/news/ 97may $2 / 21$.

18 SOUTH AFRICAN LABOUR FORCE SURVEY P0210 (2001) February 2001, Statistics South Africa.

19 South African Police Services Crime Statistics on-line at: http://www.saps.co.za/8 crimeinfo/398/table of contents.html

SAPS (1996a) Hijacking of Passenger Vehicles.

SAPS (1996b) The National Serious Crime Picture.

SAPS (1996c) Rape. 